\title{
Anti-Epileptic Drugs, Would They be the Cause of Heterotopic Ossification
}

\author{
Saloua Khalfaoui*1 and Hafid Arabi ${ }^{2}$ \\ ${ }^{1}$ Hôpital Militaire d'instructions Mohamed V, Rabat, Morocco \\ ${ }^{2}$ Hôpital Militaire Avicenne Marrakech, Marrakech, Morocco
}

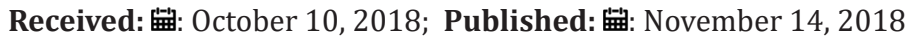

*Corresponding author: Saloua Khalfaoui, Service de médecine physique et Réadaptation Fonctionnelle (MPR), Hôpital Militaire d'instructions Mohamed V, Rabat, Morocco

\begin{abstract}
Etiopathogenesis of Heterotopic ossification or paraosteoarthropathy is unknown, all speculations remain open. Epilepsy and anti-epileptic drugs have never been mentioned as a risk factor. We report the case of an epileptic patient operated several times for fracture of the right humeral head. He was treated by anti-epileptic (Valproic Acid). He developed a stiffness of the right shoulder. Imaging showed a heterotopic ossification. Through this observation, we have tried to answer the question of the origin of the appearance of the heterotopic ossification; this genesis is multifactorial with a role of the anti-epileptic whose Valproic Acid.
\end{abstract}

Keywords: Heterotopic Ossification; Anti-Epileptic Drugs; Valproic Acid; Shoulder; Epilepsy

Abbreviations: HO: Heterotopic Ossification; AEDs: Anti-Epileptic Drugs; CT: Computed Tomography; BM: Bone Marrow; MSC: Mesenchymal Stromal Cells

\section{Introduction}

Heterotopic ossification (HO) or paraosteoarthropathy is called neurogenic when it occurs as a result of central or peripheral nervous system involvement. A HO may also occur in a context of bone trauma or burns or in an orthopedic context [1]. Epilepsy and anti-epileptic drugs (AEDs) have never been mentioned as a risk factor.

\section{Case Description}

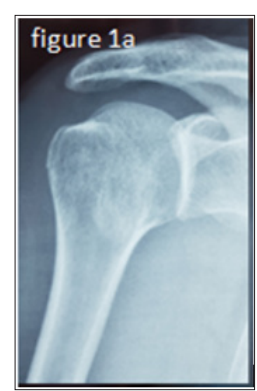

Figure 1a: X-ray of the face with posterior dislocation of the shoulder.

A30 years old patient with no antecedent had a painful posterior dislocation of the right shoulder, due to an initial epileptic seizure
(Figure 1a). Neurological examination and cerebral Computed tomography (CT) showed no abnormality; he was treated by an anti-epileptic (Valproic Acid). The reduction of the posterior dislocation with sedation caused a fracture of the head without neurological injury (Figure 1b). The patient was operated on three occasions: he was operated on day one for the initial fracture (anterior approach, Figure 1c). The postoperative was marked on day seven by a superficial cutaneous infection (C-reactive protein at $54 \mathrm{mg} / \mathrm{L}$, normal complete blood count, and preservation of the general state). The sampling showed an enterobacter clouaca complex. He was treated by antibiotherapy based on gentamicin $160 \mathrm{mg} / \mathrm{L}$ for five days and ciprofloxacin for two months, the evolution was remarkable after one month. He was operated at day 7 for insufficient reduction of the humeral head (removal of material and introduction of new material (Figure 1d, anterior and posterior approach). There was no sign of deep infection. The progress was marked by the absence of recurrence of epilepsy since the first crisis and stiffness. At day 30 of dislocation, there was an appearance of periarticular ossification compromising the function of the shoulder (Figures 1e \& 1f). Computed tomography (CT) of the shoulder showed the localization of ossification (Figures 2a-2c). At day 45, Rehabilitation sessions were done but 
without improvement. He was operated at day 60 of the last act for the removal of the material without sign of infection (anterior approach). Currently, the patient always keeps stiffness on the activities of the daily life, the hand-mouth is possible but the limitation of the abduction and the external rotation makes difficult hand-neck. Scintigraphic evaluation of osteoblastic activity would be realized to decide on a possible arthrolysis of the shoulder.

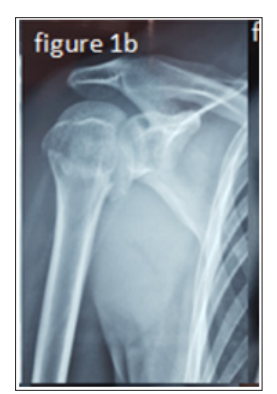

Figure 1b: Fracture of the head of the shoulder after reduction with sedation.

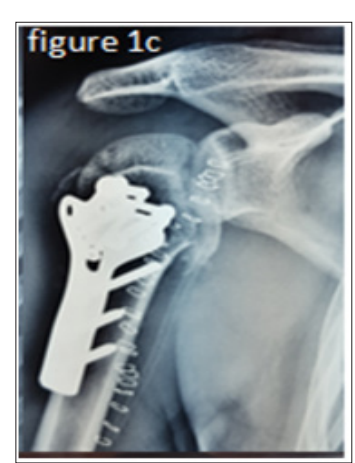

Figure 1c: Setting up the first material at day one.

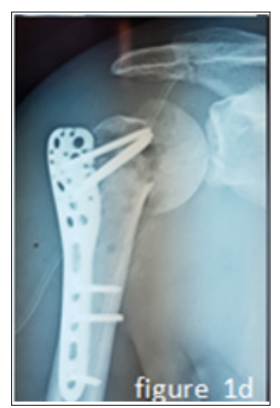

Figure 1d: Implementation of the second material at day seven.

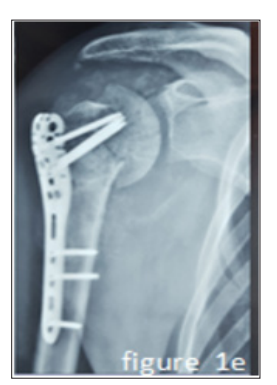

Figure 1e: Heterotopic ossification at the thirtieth day.

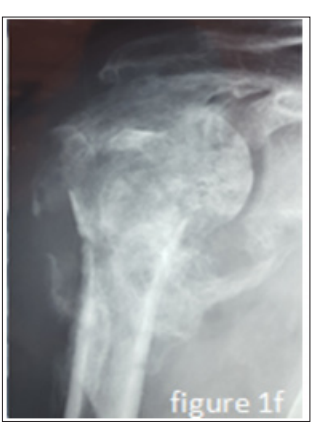

Figure 1f: Heterotopic ossification in the fifth month.

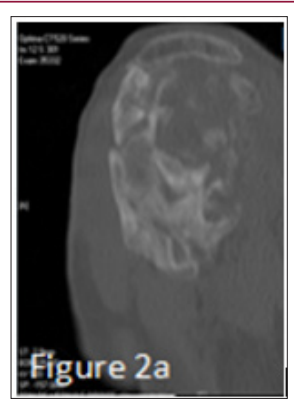

Figure 2a: Heterotopic ossification on a sagittal cross section in computed tomography (CT) of the shoulder.



Figure 2b: Computed tomography (CT) showing Heterotopic ossification.

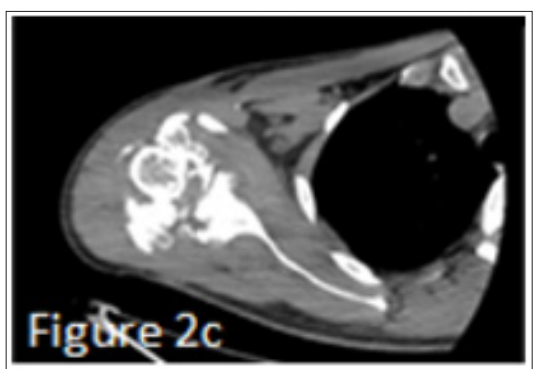

Figure 2c: Computed tomography (CT) cross section through the surgical collar of the shoulder.

\section{Discussion}

We distinguish metastatic calcification, dystrophic calcification, and ectopic ossification. In ectopic ossification, there is: progressive myositis (congenital disease), post-traumatic ossification myositis, sequelae of burns, complications of surgery, and neurological lesion. The etiopathogenesis of $\mathrm{HO}$ is not yet known exactly, although there 
are several models of HO induction in animals [1], like the technique of injecting bone marrow into a muscle [2]. Among the factors of the formation of the HO, some authors have evoked vascular changes related to a dysfunction of the autonomic nervous system [3]; the existence of a prolonged immobilization, it is responsible for a bone demineralization resulting in a release of calcium which can participate in the calcification of the neighboring soft tissues [4]; bone microtrauma, due to repeated passive kinesitherapic manipulations and going beyond the articular amplitudes, are responsibles for a local inflammatory state, favoring the release of humoral factors that stimulate osteogenesis [4]; the existence of sepsis, or a pressure ulcer leads to the appearance of a inflammatory syndrome, which also promotes the onset a HO [4]; spastic hypertonia would act by inducing bone micro-traumas linked to the stresses exerted by muscle contractures on the articulation [5].

In our case, we note several factors whose connection is unknown: the various surgical procedures, kinesitherapic manipulations, prolonged immobilization and a local inflammatory state such as sepsis. We eliminated the role of kinesitherapy that began after the onset of HO, we doubt about the role of infection because it was cutaneous and superficial; there was no damage to the central nervous system to incriminate spasticity. Could Epilepsy as a central neurological disorder promote $\mathrm{HO}$ with the intervention of other factors? We wonder what role the anti-epileptic drugs (AEDs), could play. Epilepsy is a common neurological disorder worldwide and AEDs are always the first choice for treatment, the treatment of our patient was Valproic Acid. However, more than $50 \%$ of patients with epilepsy who take AEDs have reported bone abnormalities [6]. In our observation, we believe that the multiple surgeries have favored $\mathrm{HO}$ by release of bone tissue and the intervention of anti-epileptic drugs as Valproic Acid. We wonder about the role of mesenchymal stromal cells in the genesis of $\mathrm{OH}$ after the fracture of the humerus. The mesenchymal stromal cells of adipose tissue were initially isolated from the bone marrow (BM-MSC) [7]. BM-MSC are multipotent, that is, they can differentiate into various types of cells derived from the mesoderm [8] (bone, cartilage, adipose tissue); these cells have great potential for cellular therapies as they can be directed to differentiate into certain lineages [9].

Recent studies have reported that Valproic Acid influences osteogenesis in vivo and in vitro $[10,11]$, the study indicates that Valproic Acid increase the recruitment of Mesenchymal stromal

\section{ISSN: 2574-1241}

DOI: 10.26717/BJSTR.2018.11.002040

Saloua Khalfaoui. Biomed J Sci \& Tech Res

This work is licensed under Creative

Commons Attribution 4.0 License

Submission Link: https://biomedres.us/submit-manuscript.php cells (MSC) to sites of injury without compromising their ability to proliferate or differentiate [12]. Valproic Acid promoted osteoblastic differentiation [10]. Etiopathogenesis of $\mathrm{HO}$ is unknown, all speculations remain open, and the links that can exist between several clinical entities deserve clarification. In the case of a stiff shoulder post traumatic or postoperative consider making radiography and do not hastily think of a capsulate. Further investigation is warranted with regard to the predisposing a factor of $\mathrm{HO}$.

\section{References}

1. Tarall A, Lefebvre S, Sengler J (2009) Paraosteoarthropathie survenant dans un contexte de pathologie neurovasculaire. Journal de readaptation medicale 29(3): 105-117.

2. Lotta S, Scelsi L, Scelsi R (2001) Microvascular changes in the lower extremities of paraplegics with heterotopic ossification. Spinal Cord 39(11): 595-598.

3. Van Kuijk AA, Geurts ACH, Van Kuppevelt HJM (2002) Neurogenic heterotopic ossification in spinal cord injury. Spinal Cord 40: 313-326.

4. Vanden Bossche L, Vanderstraeten G (2005) Heterotopic ossification: a review. J Rehabil Med 37(3): 129-136.

5. Fan HC, Lee HS, Chang KP, Lee YY, Lai HC, et al. (2016) The impact of Anti-Epileptic Drugs on Growth and Bone Metabolism. Int J Mol Sci 2016; 1:17(8): E1242.

6. Friedenstein AJ, Deriglasova UF, Kulagina NN, Panasuk AF, Rudakowa SF, et al. (1974) Precursors for fibroblasts in different populations of hematopoietic cells as detected by the in vitro colony assay method. Exp Hematol 2(2): 83-92.

7. Dominici M, Le Blanc K, Mueller I, Slaper-Cortenbach I, Marini F, et al. (2006) Minimal criteria for defining multipotent mesenchymal stromal cells. The Interna- tional Society for Cellular Therapy position statement. Cyto-therapy 8(4): 315-317.

8. Bertheuil N, Chaput B, Ménard C, Varin A, Garrido I, et al. (2015) Adiposederived stromal cells: History, isolation, immunomodulatory properties and clinical perspectives. Annales de Chirurgie Plastique Esthétique 60(2): 94-102.

9. Hatakeyama Y, Hatakeyama J, Takahashi A, Oka K, Tsuruga E, et al. (2011) The Effect of Valproic Acid on Mesenchymal Pluripotent Cell Proliferation and Differentiation in Extracellular Matrices. Drug Target Insights 5: 1-9.

10. Ohta T, Wergedal JE, Gruber HE, Baylink DJ, Lau KH (1995) Low dose phenytoin is an osteogenic agent in the rat. Calcif Tissue Int 56(1): 4248.

11. Marquez-Curtis LA, Qiu Y, Xu A, Anna Janowska-Wieczorek (2014) Migration, Proliferation, and Differentiation of Cord Blood Mesenchymal Stromal Cells Treated with Histone Deacetylase Inhibitor Valproic Acid. Stem Cells Int 2014: 1-14.

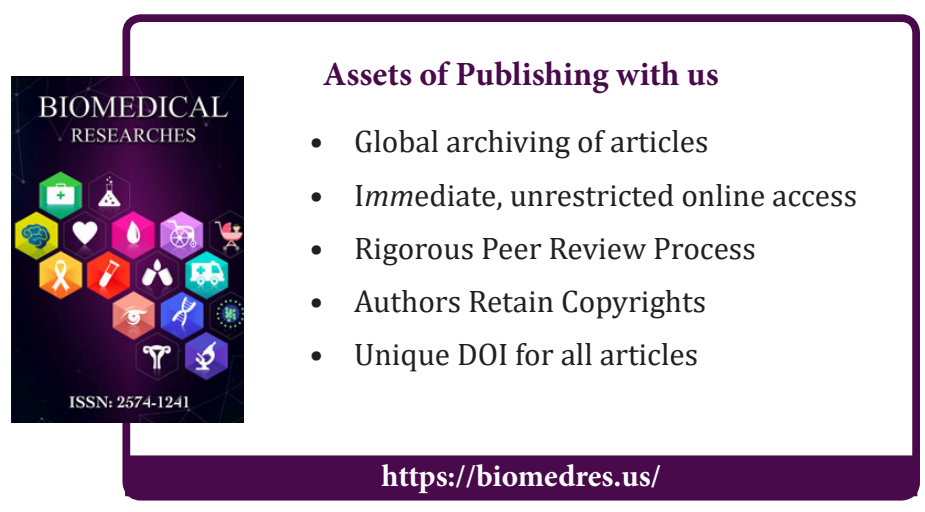

Cite this article: Saloua K Hafid A. Anti-Epileptic Drugs, Would They be the Cause of Heterotopic Ossification. Biomed J Sci\&Tech Res 11(1)- 